\title{
O EGRESSO DA ESCOLA TÉCNICA DE SAÚDE DA UNIMONTES: CONHECENDO SUA REALIDADE NO MUNDO DO TRABALHO
}

\author{
THE GRADUATE FROM THE TECHNICAL SCHOOL OF HEALTH OF UNIMONTES: GETTING TO \\ KNOW YOUR REALITY IN THE WORLD OF WORK
}

\author{
Marília Borborema Rodrigues Cerqueira ${ }^{1}$ \\ Maria Patrícia Silva ${ }^{2}$ \\ Zaida Ângela Marinho de Paiva Crispim ${ }^{3}$ \\ Élika Garibalde ${ }^{4}$ \\ Eveline Andries de Castro ${ }^{5}$ \\ Daiane Ribeiro Almeida $^{6}$ \\ Fabiano Rodrigues Maynart ${ }^{7}$
}

Resumo Este artigo apresenta resultados do acompanhamento de egressos da Escola Técnica de Saúde da Universidade Estadual de Montes Claros, discutindo a contribuição oferecida na formação e avaliação feita pelos egressos, bem como a situação profissional em que se encontram. Como metodologia quantitativa, utilizou-se um survey telefônico, por meio de Entrevista Telefônica Assistida por Computador, abordando egressos dos cursos técnicos em análises clínicas, enfermagem, farmácia, higiene dental, radiologia e atividades do comércio ofertados entre junho de 2003 e maio de 2007. Os principais resultados indicam que $78,3 \%$ dos egressos do setor saúde estão no mercado de trabalho, 73,9\% recebem de um a dois salários mínimos, $85 \%$ reconhecem que os conhecimentos construídos contribuem para a melhoria da qualidade do trabalho e $97,2 \%$ avaliam positivamente corpo docente e instituição, valorizando a oportunidade de qualificação profissional, já que encontram dificuldades diversas para estudar. Conclui-se que a escola cumpre sua função educativa e social ao qualificar profissionais inseridos nos serviços de saúde, possibilitar a inserção e a permanência no mercado de trabalho e oferecer oportunidades de educação profissional para trabalhadores residentes em municípios do norte de Minas Gerais e outras regiões. A educação desenvolvida pela escola busca inclusão, alcance de cidadania e educação crítico-reflexiva. Palavras-chave egressos; educação profissional; trabalho.
Abstract This article presents results of the monitoring of graduates of the School of Health Technology at the State University of Montes Claros, discussing the contribution offered in the education and evaluation done by the students, as well as the professional level in which they find themselves. A telephone survey was used as quantitative methodology, using computer assisted telephone interviews which addressed graduates of technical courses in clinical laboratory science, nursing, pharmacy, dental hygiene, radiology, and trade, offered between June, 2003 and May, 2007. The main results indicate that $78.3 \%$ of graduates in the health sector are in the labor market, $73.9 \%$ receive one to two minimum wages, $85 \%$ recognize that the knowledge acquired helped improve the quality of their work, and $97.2 \%$ positively evaluated the faculty and the institution, enhancing the chances of qualification, since they have to overcome many obstacles in order to study. It was concluded that the school fulfills its educational and social role by qualifying professionals placed in health services, enabling their insertion and permanence in the labor market and providing opportunities of professional education for workers living in cities of northern Minas Gerais and other regions. The education developed by the school seeks inclusion, citizenship, and critical-reflexive education.

Keywords graduate; professional education; work. 


\section{Introdução}

O acompanhamento de egressos do ensino profissionalizante é uma atividade legitimada e reconhecida como uma maneira de estabelecer sintonia entre o mundo do trabalho e a escola. A lei n. ${ }^{\circ}$ 9.394/96 - Lei de Diretrizes e Bases da Educação Nacional (LDB) - e o decreto n. ${ }^{\circ} 2.208 / 97$ afirmam a importância de ajustar a educação profissional às necessidades do mundo do trabalho. De forma complementar, a portaria n. ${ }^{\circ}$ 646/97 regulamenta ambas as legislações e ressalta, no artigo 9, parágrafo único: “Os mecanismos permanentes deverão incluir sistema de acompanhamento de egressos e de estudos de demanda de profissionais" (Brasil, 1997a).

Com os estudos sobre os egressos, é possível identificar qual a contribuição da escola na formação dos profissionais, conhecer a situação profissional, permitir ao egresso avaliar a formação que recebeu, entre outras questões. Assim, dois pontos merecem destaque em uma pesquisa de egressos: o primeiro diz respeito ao mundo do trabalho, considerando que um dos focos da pesquisa é avaliar a integração dos egressos nas ocupações que compõem o processo produtivo; o segundo refere-se ao processo educativo, porque estudos sobre egressos podem ser subsídios para estabelecer os objetivos de cursos, currículos, docentes e escolas. Neste estudo, 8 buscouse contemplar os pontos apresentados ao se desenvolver uma pesquisa de egressos da Escola Técnica de Saúde (ETS) da Universidade Estadual de Montes Claros (Unimontes), em Minas Gerais.

A ETS/Unimontes foi criada com o objetivo de atender a uma demanda social de formação confirmada por pesquisa realizada em 1990/1991. Os principais resultados dessa pesquisa indicaram a necessidade de se criar uma escola específica para o setor saúde, de caráter permanente, reconhecida pelo sistema educacional e ligada ao Sistema Único de Saúde (SUS). O interesse e a preocupação da ETS/Unimontes em oferecer uma educação profissional comprometida com a sociedade e com o aluno e a importância do acompanhamento de egressos foram as justificativas para a realização do estudo que ora se apresenta.

Para tanto, foi utilizada metodologia quantitativa, a Entrevista Telefônica Assistida por Computador (Etac), um survey telefônico. As entrevistas foram realizadas com os egressos da ETS/Unimontes que concluíram cursos técnicos no período entre junho de 2003 a maio de 2007.

Os principais resultados permitem avaliar o trabalho desenvolvido pela escola e definir novas tarefas, tendo como eixo norteador o fato de a educação profissional para a saúde possuir propriedades específicas e o trabalho em saúde apresentar características próprias, não seguindo "uma lógica rígida como a racionalidade dos critérios de produção material" (Ramos, 2002, p. 57). 


\section{A relação do trabalho com a educação profissional}

Ao longo dos tempos, pode-se notar diferentes maneiras de se apreender o conceito de formação profissional, à medida que tanto o mercado de trabalho quanto a tecnologia e as formas de organização do trabalho e da produção foram se modificando. Na contemporaneidade, com a reestruturação produtiva, a formação profissional transformou-se em um fator imprescindível, com a chegada de novas tecnologias e novas formas de organizar e gerir o trabalho. Conforme Brasil (2007), os processos de planejamento e de qualificação são repensados; o que anteriormente caracterizava-se pela predominância do trabalho prescrito e pouca autonomia passa a exigir do trabalhador maior intelectualização, conhecimentos técnicos e qualificação profissional.

A globalização, a sociedade do conhecimento, a incorporação de novas tecnologias e a reforma do Estado propõem novos desafios aos responsáveis pelas políticas econômicas e sociais. Um destes desafios é a tarefa de revisar os modelos de educação profissional. Ela é concebida por muitos como uma resposta ao mercado de trabalho, para a adequação dos menos abastados ao sistema produtivo capitalista. No entanto, conforme Pereira e Ramos:

Apesar da hegemonia herdada de uma política de educação profissional que concebe a educação como forma de adaptação dos trabalhadores ao existente, às condições objetivas da produção e reprodução do próprio capitalismo, também se formou um projeto contra-hegemônico de formação dos trabalhadores da área da saúde em nosso país, cuja meta é entender as condições históricas que produzem e reproduzem o próprio sistema capitalista periférico e dependente (...) (Pereira e Ramos, 2006, p. 13).

Ações voltadas para uma educação de qualidade geram retornos, em termos pessoais e de produtividade, com consequente desenvolvimento econômico e bem-estar social para o país, tanto pelo aumento de renda quanto pela possibilidade de inserção social para o sujeito.

Amartya Sen (2000) compreende que oportunidades sociais, como a educação, têm influência na liberdade de os indivíduos viverem melhor, participando das atividades econômicas e da política.

Oportunidades sociais são as disposições que a sociedade estabelece nas áreas de educação, saúde, etc., as quais influenciam a liberdade substantiva de o indivíduo viver melhor. Essas facilidades são importantes não só para a condução da vida privada (...), mas também para uma participação efetiva em atividades econômicas e políticas. Por exemplo, o analfabetismo pode ser uma barreira formidável à participação em atividades econômicas que requeiram produção segundo especificações ou que exijam rigoroso controle de qualidade (Sen, 2000, p. 56). 
O discurso ideológico neoliberal relaciona a educação-emprego em torno da noção de 'empregabilidade'. Assim, quanto melhor a sua escolaridade, mais 'empregável' é o sujeito, noção que transfere para o indivíduo total responsabilidade sobre sua educação e qualificação, e a consequente possibilidade de permanecer empregado. No entanto, Santomé (2003) destaca uma nova característica da sociedade atual: muitos trabalhadores com várias qualificações estão desempenhando atividades inferiores à formação que possuem, pois as empresas não têm interesse em pagar um salário consoante com a formação. "Naturalmente, a educação não é o único e nem o principal aspecto da transformação das sociedades (...)" (Santomé, 2003, p. 29).

“Já o conceito marxiano de qualificação profissional pode ser entendido como uma articulação entre as condições físicas e mentais que compõem a força de trabalho, utilizadas em atividades voltadas para valores de uso" (Pereira e Ramos, 2006, p. 15). De acordo com as autoras, é importante a percepção da qualificação profissional como processo educativo que é parte da formação humana, ou seja, não se pode furtar de sinalizar que, como instrumento contra-hegemônico ao capitalismo, ela deve ser vislumbrada também na sua relação com a cultura. Segundo Frigotto (2002), o trabalho não pode ser reduzido à simples remuneração de uma tarefa, mas como um direito relacionado a uma profissão, o direito de qualificação.

Dessa forma, qualificar-se é uma tarefa complexa. O sujeito, neste contexto de mudanças econômicas, sociais, políticas e culturais impostas pela reestruturação produtiva ou, conforme nomeou Harvey (1998), pela acumulação flexivel, precisará entender a sua práxis e problematizar os acontecimentos ao seu redor (grifos do autor).

A compreensão do modo como se estrutura a qualificação profissional do ponto de vista do trabalhador e como este articula a sua história de vida, educação e trabalho são processos educativos integrantes da formação humana. Nesse contexto, é igualmente significativo o entendimento de que a qualificação pressupõe conhecimento, experiência, autonomia e condições materiais, de modo que o trabalhador desempenhe a tarefa, compreendendo de maneira abrangente os problemas a serem solucionados (Pereira e Ramos, 2006).

Os serviços serão beneficiados com profissionais qualificados; e o avanço tecnológico constante imporá ao trabalhador exigências no que se refere à formação. Há demanda de profissionais capacitados, atualizados, cidadãos críticos, para desenvolver as atividades do processo de trabalho; daí a importância dos cursos profissionalizantes.

O cidadão pouco qualificado sofre limitações que não se restringem ao aspecto profissional, uma vez que elas se ampliam na direção dos direitos e da formação de sua identidade. Além disso, esse cidadão revela o perfil da sociedade em que vive, expondo o nível de relacionamento desta sociedade com a realidade mundial. 


\section{A educação profissional no Brasil}

A formação de trabalhadores no Brasil, por muito tempo, relacionava-se a um plano secundário, sendo a aprendizagem profissional destinada aos desvalidos e entendida como de grau elementar. No entanto, com o advento da industrialização na Revolução de 1930, é destacada a relação entre trabalho e educação como problema fundamental. Nesta época, apesar da concepção de que o ensino profissional destinava-se aos menos favorecidos, percebeu-se uma mudança na medida em que as escolas passavam a ser encaradas como formadoras de técnicos capazes de exercer qualquer função na indústria.

A necessidade de preparação de trabalhadores para a indústria implicou a mudança de concepção do ensino profissional. Nesse contexto, no período da "Revolução Industrial levada a efeito no final do século XVIII e primeira metade do século XIX" afirma-se o direito de todos à educação: “Portanto, à Revolução Industrial correspondeu uma Revolução Educacional: aquela colocou a máquina no centro do processo produtivo; esta erigiu a escola em forma principal e dominante de educação" (Saviani, 2007, p. 158-159).

A Constituição de 1937 determina que o ensino profissional é dever do Estado e precisa ser cumprido com a contribuição das empresas. Proporcionou, ainda, a Lei Orgânica do Ensino Profissional e a criação de entidades especializadas, como o Serviço Nacional de Aprendizagem Industrial (Senai), em 1942, e o Serviço Nacional de Aprendizagem Comercial (Senac), em 1946.

A educação profissional em saúde foi permitida legalmente no Brasil somente em 1961, com a promulgação da lei n. ${ }^{\circ} 4.024 / 61$ (Lei de Diretrizes e Bases da Educação Nacional). Em relação à formação de trabalhadores da saúde, e por meio dessa mesma lei, o curso de enfermagem passou a ser de nível superior. Apenas em 1966 foi criado o curso técnico em enfermagem, o primeiro na área da saúde.

Para Pereira e Lima (2006), até então a educação profissional era tratada especificamente como formação de professores e de profissionais para a indústria, o comércio e a agricultura. Em se tratando da área da saúde, havia apenas trabalhadores com treinamentos essencialmente práticos, desenvolvidos por meio de atividades em orfanatos, domicílios e hospitais. Os mais experientes repassavam as orientações para os aprendizes pela prática, não se preocupando com as informações teóricas. Segundo as autoras (Pereira e Ramos, 2006, p. 22), “Há uma redefinição simultânea do objeto, da atividade do trabalho, dos meios do trabalho, do saber e da educação na formação/qualificação dos profissionais de saúde."

Na década de 1970, a lei n. ${ }^{\circ} 5.692 / 71$ estabeleceu compulsoriamente a profissionalização como finalidade única para o ensino de Segundo Grau, 
ou seja, ficou estabelecida a educação profissional integrada ao ensino secundário. Na área da saúde, os educadores comprometidos com a formação dos trabalhadores em saúde visualizaram nessa lei caminhos através do ensino de suplência para que fosse possível uma qualificação profissional por meio dos centros formadores, que posteriormente seriam as Escolas Técnicas de Saúde do Sistema Único de Saúde (Etsus). Consequente a esse processo, na década de 1980, foi criado o Projeto de Formação Larga Escala e viabilizados os Centros de Formadores do SUS, que surgiram, conforme Pereira e Ramos (2006, p. 37), “(...) devido à necessidade de promoção e melhoria da formação profissional de trabalhadores de nível médio e fundamental da saúde - que era realizada, majoritariamente, pelas instituições de saúde".

A reforma dos anos 1990, com a nova LDB (lei n. ${ }^{\circ}$ 9.394/96) e o decreto federal n. ${ }^{\circ}$ 2.208/97, rompeu a integração entre Ensino Médio e educação profissional e definiu a educação profissional como necessariamente paralela e complementar à educação básica. Assim, o aluno deverá cursar o ensino profissional após o Ensino Médio ou cursá-lo concomitantemente ao Ensino Médio.

No entanto, as transformações consequentes da reestruturação produtiva passam a exigir uma nova política educacional, uma proposta de articulação entre ciência, cultura e trabalho, como elementos norteadores para o desenvolvimento nacional.

\section{Educação profissional na ETS/Unimontes}

A problemática da formação de trabalhadores de nível médio e elementar em saúde na região norte de Minas Gerais foi detectada a partir de uma pesquisa, em 1991, que levou à criação da Escola Técnica de Saúde da Unimontes, como alternativa para solucionar o problema de formação desses trabalhadores. A implantação do SUS e a consolidação da Reforma Sanitária no norte de Minas passavam, necessariamente, pelo tratamento adequado de várias questões cruciais, como a dos recursos humanos (Unimontes, 1991).

A criação da escola técnica objetivou mudar o cenário de formação desses trabalhadores, considerando que um preparo de qualidade deve ser um meio pelo qual se busca a construção, transformação e consolidação do serviço de saúde prestado à população.

A ETS/Unimontes, ao longo de sua história, esteve preocupada em propiciar uma educação profissional que vai além da simples capacitação dos trabalhadores para manusear as técnicas de trabalho. A educação profissional deve ocupar-se e ajustar-se às necessidades sociais. Vale lembrar que não se pode limitar os projetos educativos às demandas imediatas do sistema de produção capitalista, ou seja, do mercado de trabalho. 
Se é certo que a educação profissional não tem o poder de corrigir distorções estruturais e alavancar processos retificadores de desequilíbrios sociais, também é correto afirmar que esta não pode ser pensada fora dos interesses e necessidades sociais concretas e desarticulada das políticas de emprego e renda que garantam um desenvolvimento econômico e social mais harmonioso (Fidalgo e Machado, 1999, p. 105).

Como afirma Frigotto (2002), a educação objetiva capacitar os educandos a ter uma leitura crítica da realidade capitalista e lutar por novas relações sociais, e ser formadora de atores sociais, cidadãos capazes de se mostrarem como protagonistas da emancipação humana. O trabalho desenvolvido pela ETS/Unimontes busca orientar-se por essa visão de educação.

\section{Estudos de egressos como ação reflexiva sobre a educação}

Os estudos de acompanhamento de egressos são uma possibilidade de análise sobre a educação e oferecem elementos que permitem à escola técnica desenvolver cursos adequados às reais necessidades da sociedade, adaptar os currículos dos cursos, conhecer as profissões que têm maior demanda e, especialmente, proporcionar uma educação profissional comprometida com a cidadania e os serviços de saúde.

Sakai e Cordoni Júnior (2004) mostram que os estudos com egressos vêm sendo valorizados em avaliações de programas educacionais e, atualmente, a avaliação de ex-alunos tem sido recomendada nas políticas de recursos humanos. Os estudos com egressos possibilitam estabelecer um elo entre a formação e a prática, ao avaliarem o curso feito e o exercício da profissão.

Os ex-alunos são agentes ativos no processo de mudanças de suas escolas, bem como na determinação das necessidades no tocante à educação permanente. Desta forma, os egressos podem contribuir para uma melhor compreensão do Modelo Assistencial e Mercado de Trabalho em que atuam e as reformulações curriculares (...), principalmente de seu aparelho formador (Sakai e Cordoni Júnior, 2004, p. 36).

De acordo com Deluiz (2003), acompanhar egressos oferece elementos não apenas para avaliar a ação formadora, mas deve ser utilizado como um instrumento que avalie a qualidade e o uso social do conhecimento adquirido, em termos de ampliação do exercício da cidadania.

Os trabalhadores são atores centrais da ação nos serviços de saúde, então, melhorar a qualidade da educação oferecida é melhorar a qualidade do serviço prestado. Logo, essa pesquisa sobre os egressos permitiu obter 
dados que subsidiarão a reflexão sobre a práxis da educação oferecida e as ações voltadas para o fortalecimento da educação profissional na ETS/Unimontes.

\section{Metodologia}

Este estudo é descritivo-exploratório e utilizou-se de um método quantitativo, denominado Entrevista Telefônica Assistida por Computador (Etac), um survey telefônico. De acordo com Santos (1991), a pesquisa exploratória é baseada na pressuposição de que através do uso de procedimentos relativamente sistemáticos pode-se desenvolver explicações relevantes a um determinado fenômeno. O estudo descritivo apresenta a realidade, oferecendo uma exposição e descrição dos fatos.

No que se refere ao survey, segundo Fink e Kosecoff (1985 apud Günther, 2003), o termo é definido como "método para coletar informações de pessoas acerca de suas ideias, sentimentos, planos, crenças, bem como origem social, educacional e financeira". O survey telefônico por amostragem apresenta vantagens que contribuem para agilizar e minimizar os custos da pesquisa, tais como: rapidez nos resultados; facilidade de acesso aos indivíduos que serão abordados pela pesquisa; eliminação de despesas feitas com viagens (transporte, hospedagem e alimentação), além de evitar o deslocamento da equipe durante o processo de coleta de dados. "Embora também precise de treinamento dos entrevistadores, reduz-se consideravelmente o uso de papel, visto que as perguntas são apresentadas na tela do computador para o entrevistador, que as lê para o entrevistado" (Günther, 2003, p. 32).

Neste trabalho, o survey telefônico Etac foi viabilizado pela utilização de software específico (Access), com a organização do banco de dados (cadastro dos egressos e contatos) e versão eletrônica do questionário. Posteriormente, as informações coletadas foram organizadas em SPSS, um software que organiza dados estatísticos.

Quanto ao universo de estudo, foram incluídos os egressos da ETS/Unimontes que concluíram seus cursos entre junho de 2003 a maio de 2007 - limites temporais justificados pelo fato de os egressos cujos cursos encerraram-se até maio de 2003 terem sido objeto de outro estudo (não publicado). Assim, o universo de estudo compreendeu ex-alunos dos cursos de: educação profissional técnica de nível médio em análises clínicas, enfermagem, farmácia, higiene dental, radiologia médica e atividades do comércio.

Vale ressaltar que o Centro de Ensino Médio e Fundamental (Cemf), da Unimontes, onde está inserida a ETS, oferece cursos na área do comércio, viabilizados pela parceria Unimontes e a Câmara dos Dirigentes Lojistas 
(CDL) do município de Montes Claros. Com o intuito de possibilitar a oferta de informações para a revisão da prática docente de todo o Cemf, esta pesquisa contemplou, na amostra, também esse grupo de egressos, cujos resultados foram analisados separadamente. Os entrevistados são tratados em todo o documento pelas seguintes nomenclaturas: egressos, ex-alunos, profissionais e trabalhadores.

A amostra de 212 elementos foi extraída de um universo de 681 egressos, distribuídos proporcionalmente por curso: análises clínicas (trinta concluintes, 11 na amostra) e, respectivamente, enfermagem (396 e 107), farmácia (49 e 18), higiene dental (85 e 31), radiologia médica (35 e 13) e atividades do comércio ( 86 e 32 ). O pré-teste foi realizado com egressos residentes no município de Montes Claros.

A determinação da amostra pautou-se pelas considerações: o grau de heterogeneidade nos grupos de itens similares; o tamanho finito da população; o erro máximo permitido; o percentual com o qual o fenômeno se verifica. Para efeito de cálculo da amostra, e tendo em vista que a variância é desconhecida, utilizou-se a formulação matemática proposta por Stevenson (1981):

$$
n=\frac{z^{2} \cdot \xi \cdot(1-\xi) N}{(N-1) \cdot e^{2}+z^{2} \xi \cdot(1-\xi)}
$$

$\mathrm{n}=$ tamanho $\mathrm{da}$ amostra

$z=$ o nível de confiança

$\xi=$ a percentagem com que o fenômeno ocorre

e $=$ o erro máximo permitido

$\mathrm{N}=$ o tamanho da população

Tendo em vista que não se sabe o valor específico de $\xi$, estimou-se $\xi$ igual a 0,5. Para ' $\mathrm{e}$ ' igual a $5 \%$ e limite de confiança igual a $95 \%$. A amostragem foi proporcional estratificada aleatória, fundamentada na existência de um universo composto por estratos, e os elementos da amostra foram sorteados com o uso de Tabelas de Números Aleatórios (Crespo, 1997). Somente no caso dos egressos de enfermagem, o limite de confiança foi igual a $92 \%$, pela impossibilidade de formar uma amostra maior.

Em atendimento à resolução n. ${ }^{\circ}$ 196/96 do Conselho Nacional de Saúde (CNS), o projeto de pesquisa teve parecer favorável do Comitê de Ética em Pesquisa da Unimontes, sendo aprovado em 12 de julho de 2006, conforme parecer n. ${ }^{\circ}$ 329/06, após aprovação pela Comissão Nacional de Ética em Pesquisa (Conep), que instruiu sobre os procedimentos necessários ao desenvolvimento da coleta de dados via Etac, por meio da carta n. ${ }^{\circ} 801$ Conep/CNS/MS, de 30 de junho de 2006. 
Dentre as dificuldades enfrentadas na realização da pesquisa, destacamse: a desconfiança - que é compreensível, pois a sociedade se encontra amedrontada devido aos falsários que se fazem passar por diversas empresas, tirando proveito das informações obtidas; a falta de tempo e interesse em participar - alguns egressos recusaram a responder ao questionário, alegando falta de tempo e demonstrando desinteresse em colaborar com a pesquisa; problemas com números de telefones - alguns egressos não foram localizados por não terem telefone próprio ou por o número estar errado ou desligado. Em outros casos, a equipe de pesquisa fez diversas tentativas de contato, procurando novos números e, por último, houve a substituição do egresso integrante da amostra. Porém, a maioria dos egressos foi receptiva ao contato da entrevista por telefone e respondeu às perguntas espontaneamente, reconhecendo a importância da pesquisa e do curso.

As análises buscaram responder à questão central da pesquisa: qual a realidade do egresso da ETS/Unimontes no mundo do trabalho e quais as suas considerações sobre a formação oferecida pela escola? Além dessa vertente que balizou os trabalhos, a pesquisa objetivou registrar informações que subsidiarão as ações da escola, permitindo uma efetiva triangulação escola-egresso-trabalho/SUS.

\section{Resultados e discussões}

No que se refere ao perfil do egresso e seu contexto de trabalho e aos cursos da área da saúde, o maior número de egressos abordado foi do curso técnico em enfermagem, justificando-se pelo convênio entre a ETS/ Unimontes e o Projeto de Profissionalização dos Trabalhadores da Área de Enfermagem (Profae), do Ministério da Saúde. Registram-se outras parcerias com o Ministério da Saúde (curso técnico em higiene dental) e com a Secretaria de Estado da Saúde do Estado de Minas Gerais (curso técnico em farmácia), via Programa de Melhoria e Fortalecimento dos Hospitais do SUS (Prohosp).

É de suma importância ressaltar o caráter descentralizado das ações da ETS/Unimontes em cidades das regiões norte, nordeste, centro-oeste, noroeste e vales do Jequitinhonha e Mucuri, no estado de Minas Gerais, possibilitando uma maior formação, constatada no depoimento a seguir:

O curso foi muito completo! Fez diferença no desempenho no meu dia-a-dia. Achei muito bom, valeu a pena, foi de grande importância! Nós não teríamos oportunidade de fazer o curso fora da cidade de Manga... (Egresso do curso técnico em enfermagem do núcleo de Manga). 
A maioria dos egressos é do sexo feminino, somando-se $85 \%$. O maior percentual de trabalhadores da enfermagem é composto por mulheres, como também o número de mulheres no mercado de trabalho tem crescido nas últimas décadas em quase todas as áreas, corroborando as assertivas de que esse aumento da participação feminina no mercado é em função da nova ordem econômica capitalista, da transição do fordismo para a acumulação flexível - houve a transformação do papel das mulheres na produção e nos mercados de trabalho, sendo as estruturas do mercado facilitadoras da exploração da força de trabalho feminina (Harvey, 1998). A feminização do mercado de trabalho é decorrente, também, da dinâmica demográfica. Ao contrário, no caso dos egressos do curso técnico em radiologia médica, destaca-se a maioria do sexo masculino, perfazendo $61,5 \%$.

Em relação à idade dos egressos, os resultados indicam grande variabilidade dos dados no intervalo de 20 a 55 anos (ou mais), respectivamente a idade mínima e a máxima. A maioria, 18,9\%, está na faixa etária de 25 a 29 anos e a idade média é igual a 37 anos. Uma parcela de $14 \%$ dos egressos com idade acima de 45 anos é do curso técnico em enfermagem. A análise da informação sobre a idade do participante privilegiou o conjunto de egressos abordados pela pesquisa, não a distribuindo por curso feito, uma vez que a variabilidade do dado não ressalta qualquer intervalo de idade diferenciado da média do conjunto.

No que se refere à raça/cor, 51,7\% dos egressos se autoclassificam como pardos; 29,4\%, brancos; e $11,1 \%$, pretos. Para as informações de raça/cor, a pesquisa adotou o mesmo procedimento da Fundação Instituto Brasileiro de Geografia e Estatística (IBGE) no Censo 2000: é uma autoclassificação com base em estudos antropológicos das relações interétnicas, contemplando-se as categorias branca, preta, parda, indígena e amarela. A inserção da informação de raça/cor nesta pesquisa justifica-se pelo fato de a Unimontes praticar a política de cotas para ingresso nos cursos de graduação e, ainda, de acordo com Lopes (2007), é fundamental pensar o conceito de raça como recurso imprescindível na organização dos princípios das sociedades.

Em se tratando da escolaridade dos ex-alunos da ETS/Unimontes, o maior contingente possui Ensino Médio completo, um número absoluto de 162 egressos, o que corresponde a $90 \%$ do total. E apenas dois, ou seja, $1,1 \%$, possuem Ensino Superior completo e são egressos do curso técnico em enfermagem. À época da pesquisa, 8,9\% dos entrevistados estavam cursando o Ensino Superior. A escolaridade é, hoje, um determinante para melhorar o acesso, a inserção e a permanência do indivíduo no mercado de trabalho (Anselmi et al., 2003).

Em relação às questões sobre trabalho, os resultados indicam que $78,3 \%$ de todos os ex-alunos pesquisados conseguiram se empregar dentre estes, 17,8\% atuam na mesma área do curso concluído e 50,6\% já trabalhavam 
na área do curso anteriormente e ainda continuam. Somente 11,1\% não estão empregados na área de formação. Esses resultados corroboram a relevância do objetivo de criação da ETS/Unimontes, no sentido de capacitar trabalhadores para atuarem em sua área de formação.

Sobre a inserção dos egressos no mercado de trabalho, entre os cursos da área da saúde aquele que tem o maior percentual de ex-alunos empregados é o técnico em enfermagem, representando $86 \%$, ou seja, 92 dos egressos entrevistados. Em seguida, o curso técnico em higiene dental, com $83,9 \%$ dos ex-alunos inseridos no mercado de trabalho. Em análises clínicas, $72,7 \%$ dos egressos conseguiram trabalhar na área. Em farmácia, somam $66,7 \%$ do total pesquisado. Dos egressos técnicos em radiologia médica, 23,1\% encontram-se atuando na área - esse último percentual pode ser justificado pelo fato de a pesquisa ter feito contato somente com os residentes no município de Montes Claros.

As instituições onde os egressos estão trabalhando apresentam-se na Tabela 1. A maioria está inserida em hospitais públicos e privados, ou seja, $30,2 \%$. Ressalta-se que $84,9 \%$ do total dos entrevistados são da área da saúde; dentre esses, os que trabalham em hospitais são os técnicos em enfermagem, farmácia, radiologia médica e análises clínicas.

Tabela 1

\begin{tabular}{l|c|c}
\hline Instituição de trabalho dos egressos da ETS/Unimontes & \multicolumn{2}{c}{ Egressos } \\
\hline \multirow{2}{*}{ Especificação } & $\%$ & $\%$ \\
\cline { 2 - 3 } & 64 & 30,2 \\
\hline Hospital público ou privado & 19 & 9,0 \\
Posto de saúde & 17 & 8,0 \\
Clínica e consultório & 10 & 4,7 \\
Prefeitura Municipal & 8 & 3,8 \\
Secretaria Municipal de Saúde & 8 & 3,8 \\
Programa de Saúde da Família - PSF & 6 & 2,8 \\
Farmácia & 4 & 1,9 \\
Laboratório & 3 & 1,4 \\
Policlínica & 1 & 0,5 \\
Secretaria Estadual de Saúde & 24 & 11,3 \\
Outros & 7 & 3,3 \\
Não respondeu & 17 & 8,0 \\
Não se aplicaa & & \\
\end{tabular}

a - Egresso desempregado

Fonte: Pesquisa de campo, maio-setembro/2007.

Em relação às funções dos egressos da ETS/Unimontes, a maioria (65\%) executa apenas atividades específicas de sua função e os demais realizam ao mesmo tempo outras atividades. De uma forma mais detalhada, estratifica- 
da por curso, registram-se: daqueles com titulação de técnico em enfermagem, 42,1\% exercem a função de auxiliar de enfermagem; 25,2\%, de técnico em enfermagem; e 5,6\%, de Agente Comunitário de Saúde (ACS). Cerca de 78,5\% dos egressos do curso técnico em enfermagem executam somente as atividades específicas da sua função. Dos técnicos em higiene dental, 32,3\% exercem a função de técnico e também 32,3\%, de atendente de consultório dentário; dentre estes, 41,9\% responderam que atuam somente em atividades da função de contratação. $\mathrm{Na}$ área de análises clínicas, $27,3 \%$ assumem a função de técnico e executam somente as atividades específicas da função, enquanto 9,1\% exercem a função de auxiliar de laboratório e executam atividades além da função de contrato. Em farmácia, $16,7 \%$ trabalham como técnico em farmácia e 11,1\% como auxiliar e $66,7 \%$ responderam que realizam somente as atividades específicas da função. Em radiologia médica, 7,7\% exercem a função de técnico em radiologia médica.

Segundo o artigo 468 da Consolidação das Leis do Trabalho (CLT), o empregado tem o direito de desempenhar a função para a qual foi contratado. Esta pode ser alterada por cláusula ao longo do contrato, mantendo o nível hierárquico desde que não ocasione prejuízos ao empregado. Caso seja exercida uma função de maior salário, o empregado faz jus à diferença de valores e a alteração de atividade deve ser anotada na Carteira de Trabalho e Previdência Social (Hashimoto, 2006).

No tocante ao tempo de serviço no setor, a maioria dos egressos, 46,7\%, conseguiu se inserir no mercado de trabalho durante o período do curso ou pouco tempo depois (de um mês a cinco anos). Tendo em vista que o período da pesquisa se refere a quatro anos (junho de 2003 a maio de 2007) e os cursos técnicos da ETS/Unimontes têm duração de aproximadamente um ano e meio, os egressos com até cinco anos de tempo de serviço são os que se inseriram mais rapidamente no mundo do trabalho. Ressalta-se, também, que aqueles que têm muito tempo de serviço no setor são os já inseridos no mercado de trabalho antes de ingressarem no curso e continuam trabalhando na área após a sua conclusão. Estes são do curso de técnico em enfermagem, sendo que $25,2 \%$ estão trabalhando no setor de dez a vinte ou mais anos e 9,3\% no período de vinte a trinta ou mais anos. Este fato confirma o objetivo do Profae, desenvolvido para qualificar os trabalhadores inseridos nos serviços de saúde sem a devida titulação.

O maior contingente de egressos $(31,1 \%)$ exerce sua função com carga horária semanal de quarenta horas, ou seja, oito horas diárias. Em segundo lugar, aparecem os trabalhadores $(21,7 \%)$ que cumprem carga horária por escala de 12 por 36 horas - são os que trabalham em hospitais. Em terceiro, os profissionais $(13,9 \%)$ que cumprem um total de trinta horas por semana; e, em sequência, os egressos com carga horária semanal de 44 horas (7,8\%). Em se tratando daqueles que têm jornada de 12 por sessenta horas, o que 
corresponde a 3,9\%, esses são funcionários de hospitais públicos, sendo egressos do curso técnico em enfermagem e técnico em farmácia. No entanto, somente dois egressos na função de auxiliar de enfermagem possuem dois empregos. Logo, os resultados podem ser uma indicação de que não há acúmulo de empregos nessa jornada de trabalho de 12 por sessenta horas. E a minoria, 1,7\% para ambas, se encaixa em, respectivamente, $36 \mathrm{e}$ 48 horas semanais.

Em se tratando da forma de contratação dos egressos, tendo em vista que:

O maior problema gerado pelo trabalho precário é a vulnerabilidade do vínculo, causadora de grande insegurança no mercado de trabalho, que expõe o trabalhador a uma subcondição, impossibilitando-o de gozar plenamente seus direitos trabalhistas. Essa insegurança e a instabilidade condizem com a realidade de organização do trabalho flexível, que atende às necessidades e demandas dos contratantes de serviços, de acordo com a flutuação do mercado (Castro et al., 2007, p. 20).

Assim, buscou-se conhecer o tipo de vínculo empregatício do egresso da ETS/Unimontes. Os achados apontam um quadro de estabilidade no emprego, via ingresso no trabalho por concurso público, sendo os estatutários iguais a $34,4 \%$ do total; em segunda posição e de conformidade com o regime da lei trabalhista, somam 29,4\% dos egressos que têm como forma de contratação a CLT. A terceira modalidade de vínculo empregatício corresponde a contratos temporários, equivalentes a 11,1\%. Estratificando esses dados por curso, excluindo-se as alternativas de resposta "não respondeu" e "não sabe", a Tabela 2 apresenta as informações.

Tabela 2

\begin{tabular}{l|c|c|c|c|c}
\hline Forma de contratação dos egressos da ETS/Unimontes por curso - 2007 \\
\hline \multirow{2}{*}{ Cursos técnicos } & \multicolumn{5}{c}{ Formas de contratação (em \%)a } \\
\cline { 2 - 6 } & CLT & Estatutário & $\begin{array}{c}\text { Contr. } \\
\text { temp./Inf. }\end{array}$ & $\begin{array}{c}\text { Cargo } \\
\text { comissão }\end{array}$ & Outras \\
\hline Enfermagem & 26,2 & 43,0 & 12,2 & 0,9 & 5,6 \\
Análises clínicas & 27,3 & 27,3 & $(-)$ b & $(-)$ & 9,1 \\
Farmácia & 44,4 & 27,8 & 11,2 & 5,6 & 5,6 \\
Radiologia médica & $100,0 c$ & $(-)$ & $(-)$ & $(-)$ & $(-)$ \\
Higiene dental & 38,7 & 22,6 & 22,6 & $(-)$ & $(-)$ \\
\hline
\end{tabular}

a - Não totalizam 100\% porque foram excluídas da tabela as alternativas "não respondeu" e "não sabe".

b - O sinal ( - ) é igual a zero.

c - Referem-se ao total empregado.

Fonte: Pesquisa de campo, maio-setembro/2007. 
A maioria dos técnicos em enfermagem tem vínculo estatutário; em análises clínicas, observam-se percentuais iguais para a CLT e estatutário; nos demais, os egressos são, a maior parcela, via CLT. Ressalta-se que são vínculos empregatícios, logo, o total $100 \%$ refere-se à parcela de egressos inserida no mercado de trabalho.

Em relação à faixa salarial dos egressos da ETS/Unimontes, do contingente inserido no mercado de trabalho, 73,9\% recebem de um a dois salários mínimos (salário mínimo vigente no Brasil igual a $\mathrm{R} \$ 380,00$, em maio de 2007). Por categoria profissional e nesta faixa de salário, registramse: $80,4 \%$ dos egressos técnicos em enfermagem; $77,4 \%$ dos técnicos em higiene dental; 72,2\% dos técnicos em farmácia; 45,5\% dos técnicos em análises clínicas e, em seguida, 38,5\% dos técnicos em radiologia médica. Esses valores percebidos pelos egressos assemelham-se aos encontrados por Santos, Uchoa e Meneleu Neto (2004) no Nordeste, em torno de um salário mínimo, definindo-se como padrão salarial dominante para trabalhadores técnicos, principalmente da área de enfermagem (como também aqui, o maior percentual de ex-alunos da escola). Na faixa salarial seguinte, de três a quatro salários mínimos, encontram-se 8,3\% dos ex-alunos, sendo: 18,2\% dos técnicos em análises clínicas; 16,7\% em farmácia; 15,4\% em radiologia médica; $6,5 \%$ em higiene dental; e 5,6\% em enfermagem. E, do total pesquisado, dois egressos, $1,1 \%$, responderam que recebem de cinco a seis salários mínimos, sendo eles técnicos em enfermagem e em higiene dental. Conforme Santomé (2003) destaca, uma nova característica da sociedade atual é o fato de muitos trabalhadores, com várias qualificações, desempenharem atividades inferiores à formação que possuem, pois as empresas não têm interesse em pagar um salário condizente com a formação.

No que se refere ao ganho estritamente de ordem profissional, os resultados indicam que 73,9\% não conseguiram promoção de cargo ou benefício financeiro após o término do curso, ao passo que 13,3\% alcançaram uma dessas conquistas. No entanto, os egressos percebem outros ganhos, já citados, como a melhoria no acesso, na inserção e na permanência do trabalhador no mercado de trabalho, além de uma melhor qualidade do trabalho prestado.

$\mathrm{Na}$ área de enfermagem, as instituições de saúde exigem o certificado de técnico para a contratação na função de auxiliar. E existem trabalhadores que ingressaram em instituições como auxiliares de enfermagem e, posteriormente ao curso, exercem função de técnicos sendo remunerados como auxiliares. É um dado relevante, considerando que não há oportunidade de ascensão profissional para esses trabalhadores, de acordo com os resultados da pesquisa. Isso é caracterizado como desvio de função, uma vez que, qualificados e exercendo as atividades de técnicos, continuam a receber salários de auxiliares. O salário de auxiliar corresponde a um valor inferior 
ao do técnico de enfermagem. Essa questão remete a uma discussão maior sobre o contexto atual do mundo do trabalho.

Como resultado de um cenário de instabilidade e de mutações, que fazem par com o novo modelo de organização econômica, instaurado sob bases flexíveis de funcionamento, são vistas profundas re-configurações no sistema ocupacional e nas relações de trabalho, produtoras de novos formatos de contratação e novos regimes de trabalho. Nesse bojo, tem forte relevância um tema caro, que vem se tornando alvo de preocupações por parte de estudiosos e governantes: a precarização do trabalho (Castro et al., 2007, p. 19).

Não obstante essa questão, 79,4\% dos egressos trabalham somente em uma instituição, fato relevante para uma discussão maior sobre o mundo do trabalho. Entretanto, as razões do único emprego, na perspectiva do egresso, não foram registradas - ficando anotada na agenda de pesquisa sobre o referido tema.

\section{Qualificação profissional}

Segundo Imbernón (2005), a qualidade da instituição educacional depende dos alunos, de suas contribuições à sociedade, do que aprendeu e da maneira como aprendeu. Para contribuir com uma educação de qualidade, é preciso desenvolver, sobretudo, práticas e críticas com alternativas que possibilitem desvelar o currículo oculto da organização e descobrir outras maneiras de ver o mundo, a escola e sua organização.

Desta forma, buscou-se saber se os conhecimentos adquiridos no curso ajudaram a melhorar a qualidade do trabalho dos egressos. A maioria (85\%) respondeu que sim, o que pode ser um indicador de que a ETS/Unimontes está em consonância com a prática, o ensino e o trabalho. E 6,7\% dos egressos responderam que não. Os demais não opinaram. Lobo Neto (2003, p. 25) diz que "a educação só se realiza plenamente quando resulta em uma transformação do sujeito que se educa".

Tratando-se da avaliação dos ex-alunos em relação aos professores da ETS/Unimontes, entre alternativas 'ótimo', 'muito bom', 'bom', 'regular' e 'ruim', para a maioria dos egressos (55\%) os professores foram avaliados com 'ótimo'; para 18,9\%, 'muito bom'; e para 23,3\%, 'bom'. Este resultado positivo pode ser explicado pelo fato de os professores terem graduação, especialização lato sensu e stricto sensu nas áreas afins dos cursos técnicos da escola, como também comprometimento e experiência profissional, por estarem vinculados aos serviços de saúde, corroborando princípios e diretrizes definidos na criação e implantação da escola, no que se refere ao corpo docente (Unimontes, 1991). 
Complementando essas análises, buscou-se verificar, também, se as disciplinas do curso atenderam às necessidades da prática profissional. Do total dos entrevistados, por curso, registrou-se a seguinte distribuição dos resultados para a alternativa 'sim': dos técnicos em higiene dental, 100\% dos egressos; em enfermagem, 96,3\%; em análises clínicas, 72,7\%; em farmácia, 72,2\%; e em radiologia médica, $69,2 \%$.

Quanto à existência de profissionais na instituição de trabalho dos egressos da ETS/Unimontes sem qualificação, como um indicador de possível demanda por cursos técnicos, no total das respostas válidas, a maioria dos egressos $(60,4 \%)$ respondeu que não existem pessoas sem qualificação trabalhando na área. E 9,4\% dos ex-alunos entrevistados afirmaram que há profissionais exercendo atividades sem a devida qualificação.

$\mathrm{Na}$ área de enfermagem, $71 \%$ do total abordado responderam que não existem pessoas sem qualificação trabalhando na área. Uma possível justificativa é que o Conselho Regional de Enfermagem (Coren) tem como objetivo fiscalizar o exercício profissional, conforme rege a legislação da profissão. Na área de farmácia, para $66,7 \%$ do total pesquisado, não existem trabalhadores sem qualificação trabalhando na área. O mesmo ocorre para $64,5 \%$ dos técnicos em higiene dental, 30,8\% dos técnicos em radiologia médica e $27,3 \%$ dos técnicos em análises clínicas.

Considerando-se a importância de o profissional manter a qualificação continuamente na área da sua formação e a educação permanente, buscouse saber se a instituição em que os egressos trabalham oferece cursos de atualização ou capacitação. Do total dos entrevistados, 43,9\% responderam afirmativamente à questão. E 40\% disseram que a instituição de trabalho não oferece curso de qualificação ou capacitação. Há que se ressaltar o valor de ambas as modalidades de educação: continuada e permanente.

Um resultado relevante é que os egressos $(96,1 \%)$ acham importante a atualização e/ou qualificação, como se apresenta estratificado por tipo de curso que eles querem fazer na Tabela 3. A maioria deles, aproximados $55,6 \%$, expõe a vontade de fazer o curso de graduação, principalmente os egressos do curso técnico em enfermagem. 
Tabela 3

\begin{tabular}{l|c|c}
\hline \multirow{2}{*}{ Pretensões dos egressos da ETS/Unimontes em fazer novos cursos } \\
\hline \multirow{2}{*}{ Especificação } & No & $\%$ \\
\cline { 2 - 3 } & 125 & 55,6 \\
\hline Curso superior & 38 & 19,4 \\
Curso técnico & 26 & 13,3 \\
Dois ou mais novos cursos & 8 & 4,4 \\
Curso de atualização/reciclagem & 12 & 5,6 \\
Não tem necessidade de fazer outro curso & 3 & 1,1 \\
Não respondeu & & \\
\hline
\end{tabular}

Fonte: Pesquisa de campo, maio-setembro/2007.

Entretanto, na perspectiva dos egressos, existem empecilhos como a distância da cidade de residência à faculdade, falta de recursos financeiros, além da pouca disponibilidade de tempo, conforme registrado nas falas a seguir:

O curso deveria ser oferecido em vários turnos, porque nós enfermeiros trabalhamos em escala (Egresso 1, do curso técnico em enfermagem).

A sugestão é que o Profae oferecesse o curso a nível superior [sic] (Egresso 2, do curso técnico em enfermagem).

Dessa forma, é salutar reafirmar a função social dos cursos técnicos da ETS/Unimontes, uma vez que alguns dos ex-alunos não teriam outra oportunidade de qualificação/titulação necessária para a inserção no mercado de trabalho, se pontuadas as dificuldades de acesso físico, de ordem temporal e financeira. Ressalta-se, de igual valor, o tipo de educação oferecida pela escola: uma formação que busca a inclusão, o alcance de cidadania e uma educação crítico-reflexiva.

A seguir, registram-se as falas dos egressos sobre os anseios em relação a novos cursos.

Deveria ter mais curso de atualização para o setor de saúde em parceria com a secretaria de saúde do município (Egresso 3, do curso técnico em enfermagem).

Gostaria de me atualizar na área de pesquisa dentro das análises clínicas (Egresso 1, do curso técnico em análises clínicas).

Curso de atualização em homeopatia (Egresso 1, do curso técnico em farmácia). 
A Escola Técnica de Saúde da Unimontes deveria oferecer curso de especialização (pós-técnico) em THD (Egresso 1, do curso técnico em higiene dental).

Gostaria de fazer o curso de especialização em tomografia e ressonância. Acho que o curso deveria ter carga horária maior para termos estas disciplinas (Egresso 1, do curso técnico em radiologia médica).

\section{Resultados referentes aos egressos dos cursos técnicos em atividades do comércio}

Como já exposto anteriormente, o Cemf da Unimontes, onde está inserida a ETS, oferece cursos na área do comércio. Visando a subsidiar as ações de formação também nessa área, a pesquisa contemplou uma amostra de egressos dos cursos do comércio, cujos resultados registram-se a seguir.

O maior contingente de egressos dessa área é do sexo feminino $(59,4 \%)$, indicando a feminização igualmente nesta área do mundo do trabalho. Em se tratando das idades, os resultados indicam variabilidade entre 20 e 44 anos, sendo a média das idades igual a 28 anos. Os maiores percentuais concentram-se nas faixas etárias de 20 a 24 anos (34,4\%), 25 a 29 anos (37,5\%) e 30 a 34 anos $(15,6 \%)$. Quanto à raça/cor, os egressos se autoclassificam como pardos, $62,5 \%$; brancos, $25 \%$; amarelos, 9,4\%; e pretos, 3,1\%. A escolaridade desse grupo de egressos variou entre Ensino Médio completo, com $78,1 \%$ das respostas, e Ensino Superior incompleto, os demais 21,9\%.

Relembrando que a escolaridade é um determinante para melhorar o acesso do indivíduo ao mercado de trabalho (Anselmi et al., 2003), 93,8\% dos egressos conseguiram emprego após o término do curso, sendo que $87,6 \%$ alcançaram uma colocação ou já estavam na mesma área do curso, no comércio; $84,4 \%$ foram contratados pelo regime da CLT, e os restantes, por contratos temporários e outros. Ainda sobre o mundo do trabalho, em relação às funções, 46,9\% dos egressos são comerciários e 37,5\% atuam como auxiliar administrativo. Já $62,6 \%$ deles exercem outras atividades não específicas da sua função. Quanto o tempo de serviço no setor, variou de um mês a cinco anos, com 56,3\% do total; seis anos a dez anos, 28,1\%; 11 anos a vinte anos, 6,3\%; e acima de vinte anos, 3,1\%. Vale considerar que apenas dois egressos, dos trinta abordados pela pesquisa, encontravam-se desempregados na data da investigação.

No tocante à carga horária semanal de trabalho dos egressos, o maior percentual $(65,6 \%)$ tem jornada de 44 horas e os demais se distribuem entre trinta, 36 e quarenta horas, de forma similar. Ressalta-se uma resposta de 48 horas semanais no caso de gerente comercial, que cumpre mais de oito horas por dia. 
Quanto ao salário percebido pelos egressos da área do comércio, 65,6\% destes técnicos têm rendimentos entre um a dois salários mínimos; 21,9\%, de três a quatro; e um egresso, de cinco a seis. Apenas um não informou o seu salário.

Entre outros ganhos, os resultados apresentam que 34,4\% dos egressos conseguiram alguma promoção ou benefício financeiro após o curso e $90,7 \%$ deles utilizam os conhecimentos adquiridos no curso em suas funções técnicas. Um total de $84,4 \%$ afirma que esses conhecimentos ajudam a melhorar a qualidade do trabalho desenvolvido e percentual semelhante de egressos afirmou que as disciplinas do curso atenderam à necessidade da prática profissional.

Em se tratando de qualificação, 65,6\% dos egressos afirmaram que a instituição na qual trabalham oferece cursos de atualização/capacitação e $87,5 \%$ deles acreditam na necessidade de se fazer novos cursos. Entre os cursos pretendidos, estão o curso superior, com 78,1\% das respostas; o curso técnico, 9,4\%; e dois cursos ou mais, $6,3 \%$.

Por último, sobre a avaliação dos professores, os resultados também foram positivos, observando-se que: $40,6 \%$ dos ex-alunos avaliaram os docentes com 'ótimo' e 28,1\%, para ambas as avaliações, com 'muito bom' e 'bom'. A preocupação com o quadro de docentes é condizente aos princípios e diretrizes definidos sobre o assunto desde a implantação da escola (Unimontes, 1991).

\section{Considerações finais}

Dentre as inferências, afirma-se que a formação oferecida pela ETS/ Unimontes proporciona construir e reconstruir o conhecimento a fim de garantir a prosperidade de seus alunos, não somente pelo significativo contingente de egressos no mercado de trabalho no setor saúde $(78,3 \%)$, mas pelo fato de os conhecimentos desenvolvidos no curso ajudarem na melhoria da qualidade do trabalho (85\%), seja ele no mercado ou não. E a função social da escola é ressaltada no sentido de capacitar profissionais para atuarem em sua área de formação.

O mercado de trabalho vem sofrendo profundas mudanças nas últimas décadas, exigindo profissionais qualificados e atualizados. Assim, a educação profissional reafirma a constante preocupação com a formação de trabalhadores críticos e conscientes, ética e tecnicamente aliados a uma profissionalização; é a possibilidade de constituir um instrumento de ascensão individual e social. Por essa razão, foi importante conhecer a situação do desenvolvimento profissional dos egressos, como também suas percepções sobre a formação desenvolvida e pretensões de novos estudos. 
Nesse sentido, a oportunidade de se fazer o curso técnico na ETS/ Unimontes demonstra que ela é uma 'escola-função', e não uma 'escolaendereço', conforme denomina Izabel dos Santos em entrevista a Castro, Santana e Nogueira (2002). O fato de os conhecimentos adquiridos no curso ajudarem a melhorar a qualidade do trabalho dos egressos, a aplicabilidade dos conhecimentos adquiridos e as perspectivas de se fazer novos cursos são indicadores do cumprimento dos objetivos da ETS.

E faz-se necessário assinalar as dificuldades de ingresso no ensino superior, de acordo com a fala dos egressos. Portanto, o curso técnico foi a oportunidade de melhoria, corroborando o fato de a escolaridade ser, hoje, um determinante para o acesso, a inserção e a permanência do indivíduo no mercado de trabalho.

Não obstante este tipo de melhoria, parcelas relevantes de egressos dos cursos da área da saúde $(73,9 \%)$ e do comércio $(62,5 \%)$ não conseguiram promoção ou benefício financeiro após a conclusão do curso, gerando insatisfação, pois apostavam na qualificação almejando melhores condições de vida, traduzidas, conforme a fala deles, em maiores valores salariais.

No que diz respeito à avaliação positiva dos professores (os maiores percentuais dos egressos os classificaram nas alternativas de resposta 'ótimo', 'muito bom' e 'bom'), esses dados ressaltam a preocupação da escola com seu corpo docente e com o trabalho desenvolvido por toda a equipe. Resgatando a história da ETS/Unimontes, que foi criada atendendo a uma demanda social de formação profissional da região norte de Minas Gerais, no início da década de 1990, hoje, após 15 anos de criação, pode-se falar do compromisso com a sua função social, pois une com competência técnica a aprendizagem e o alcance da cidadania.

Vale dizer, ainda, que um dos objetivos propostos quando da implantação da ETS/Unimontes e da criação da Estação de Pesquisa foi alcançado desenvolver pesquisas de acompanhamento de egressos. Dada a importância deste tipo de estudo, no sentido de oferecer elementos para avaliar a importância da escola e de se conhecer a realidade do mundo do trabalho de seus ex-alunos, o acompanhamento de egressos oferece elementos que subsidiam a reflexão sobre a práxis da educação oferecida, significando o elo entre a escola, o mercado de trabalho e a sociedade. 


\section{Notas}

1 Coordenadora-pesquisadora da Estação de Pesquisa da Escola Técnica de Saúde e do departamento de Ciências Sociais da Universidade Estadual de Montes Claros (Unimontes), Montes Claros, Minas Gerais, Brasil. Doutoranda em Demografia pelo Centro de Desenvolvimento e Planejamento Regional da Universidade Federal de Minas Gerais (Cedeplar/ UFMG). <marilia.borborema@unimontes.br>

Correspondência: Rua Coronel Celestino, 65, Centro, Montes Claros, Minas Gerais, Brasil, CEP: 39400-014.

2 Professora-pesquisadora da Estação de Pesquisa da Escola Técnica de Saúde da Universidade Estadual de Montes Claros (Unimontes), Montes Claros, Minas Gerais, Brasil. Mestranda em Desenvolvimento Social pela Unimontes. <maria.patricia@unimontes.br>

3 Professora-pesquisadora da Estação de Pesquisa da Escola Técnica de Saúde da Universidade Estadual de Montes Claros (Unimontes), Montes Claros, Minas Gerais, Brasil. Especialista em Docência para Educação Profissional pela Unimontes e em Gerência Hospitalar pela Escola de Saúde Pública de Minas Gerais (ESP/MG). <zaida.marinho@unimontes.br>

4 Professora-pesquisadora da Estação de Pesquisa da Escola Técnica de Saúde da Universidade Estadual de Montes Claros (Unimontes), Montes Claros, Minas Gerais, Brasil. Especialista em Economia pela Unimontes. <elika.garibalde@unimontes.br>

5 Professora-pesquisadora da Estação de Pesquisa da Escola Técnica de Saúde da Universidade Estadual de Montes Claros (Unimontes), Montes Claros, Minas Gerais, Brasil. Especialista em Docência para Educação Profissional, Saúde Mental e em Metodologia do Ensino Superior pela Unimontes.<eveacastro@yahoo.com.br>

6 Bolsista de Iniciação Científica pela Rede Observatório de Recursos Humanos em Saúde (ROREHS/Opas/Ministério da Saúde). Graduanda em Ciências Sociais pela Universidade Estadual de Montes Claros (Unimontes). <kelldai@yahoo.com.br>

7 Responsável pelo banco de dados no SPSS e Excel na Estação de Pesquisa da Escola Técnica de Saúde da Universidade Estadual de Montes Claros (Unimontes), Montes Claros, Minas Gerais, Brasil. <fabianomaynart@hotmail.com>

8 Pesquisa resultante de acordo de cooperação técnica estabelecida entre o Observatório Estação de Pesquisa da Escola Técnica de Saúde da Unimontes e a Organização PanAmericana da Saúde (Opas), o Ministério da Saúde (MS) e a Rede Observatório de Recursos Humanos em Saúde (ROREHS). 


\section{Referências}

ANSELMI, Maria Luiza et al. Análise do perfil da clientela do Projeto de Profissionalização dos Trabalhadores da Área de Enfermagem (Profae). In: BRASIL. Ministério da Saúde. Secretaria de Gestão do Trabalho e da Educação na Saúde. Formação 07: avaliação do impacto do Profae na qualidade dos serviços de saúde. Brasília: Ministério da Saúde, 2003.

BRASIL. Ministério da Educação. Lei n. ${ }^{\circ}$ 9.394/96. Estabelece as Diretrizes e Bases da Educação Nacional. Brasília: Ministério da Educação, 1996. Disponível em: <www.mec.gov.br>. Acesso em: fev. 2006.

BRASIL. Ministério da Educação. Portaria MEC n. ${ }^{\circ}$ 646/97. Regulamenta a implantação do disposto nos artigos 39 a 42 da lei fede-ral n. ${ }^{\circ}$ 9.394/96 e no decreto federal n. ${ }^{\circ} 2.208 / 97$ e dá outras providências. Brasília: Ministério da Educação, 1997a. Disponível em: <http://portal.mec.gov.br/ setec/arquivos/pdf/PMEC646_97.pdf >. Acesso em: fev. 2006.

BRASIL. Ministério da Educação. Decreto n. ${ }^{\circ}$ 2.208/97. Regulamenta o $\S 2^{\circ}$ do art. 36 e os arts. 39 a 42 da lei n. ${ }^{\circ} 9.394$, de 20 de dezembro de 1996, que estabelece as diretrizes e bases da educação nacional. Brasília: Ministério da Educação, 1997b. Disponível em: <www.planalto.gov.br/ccivil_03/decreto/ D2208.htm>. Acesso em: fev. 2006.

BRASIL. Conselho Nacional de Secretários de Saúde. SUS: avanços e desafios. 2. ed. Brasília: Conass, 2007.

CAMPELlO, Ana Margarida de Mello Barreto; LIMA FILHO, Domingos Leite. Educação profissional. Dicionário da educação profissional em saúde. Rio de Janeiro: EPSJV, 2006.

CASTRO, Janete L. de et al. Programa Saúde da Família: flexibilidade e precarização no trabalho. In: CASTRO, Janete L. de (Org.). Gestão do trabalho no SUS entre o visivel e o oculto. Natal: Observatório RH Nesc/UFRN, 2007.
CASTRO, Janete L.; SANTANA, José P. de; NOGUEIRA, Roberto P. Izabel dos Santos: a arte e a paixão de aprender fazendo. Natal: Observatório RH Nesc/UFRN, 2002.

CRESPO, Antônio Arnot. Estatística fácil. 15. ed. São Paulo: Saraiva, 1997.

DELUIZ, Neise. Metodologias e resultados do acompanhamento de egressos da educação profissional. Texto apresentado no Seminário Nacional de Educação Profissional, Brasília, jun. 2003.

FIDALGO, Fernando; MACHADO, Lucília. O Planfor e a reconceituação da educação profissional. Trabalho \& Educação, n. 6, p. 72-92, jul.-dez.1999.

FRIGOTTO, Gaudêncio. A dupla face do trabalho: criação e destruição da vida. In: FRIGOTTO, Gaudêncio; CIAVATTA, Maria (Orgs.). A experiência do trabalho e a educação básica. Rio de Janeiro: DP\&A, 2002.

FUNDAÇÃO INSTITUTO BRASILEIRO DE GEOGRAFIA E ESTATÍSTICA. Retratos do Brasil: vou te contar. A revista do Censo 2000. Rio de Janeiro: IBGE, 2002.

GÜNTHER, Hartmut. Como elaborar um questionário. Série: Planejamento de Pesquisa nas Ciências Sociais, n. 1. Brasília: UnB, Laboratório de Psicologia Ambiental, 2003. Disponível em: <www.unb.br/ip/lpa/pdf/ 01questionário.pdf>. Acesso em: abr. 2006.

HASHIMOTO, Aparecida Tokumi. Alteração de função ao longo do contrato de trabalho. Última Instância Revista Jurídica, 13 nov. 2006. Disponível em <www. ultimainstancia.uol.com.br/noticia/33039. shtml>. Acesso em: 6 nov. 2007.

HARVEY, David. Condição pós-moderna. 7. ed. São Paulo: Loyola, 1998.

IMBERNÓN, Francisco. Formação docente e profissional: formar-se para a mudança e a incerteza. São Paulo: Cortez, 2005. 
LOBO NETO, Francisco José da Silveira et al. (Coord.). Formação pedagógica em educação na área da saúde: enfermagem. 2. ed. Núcleo contextual: educação, 1. Brasília: Ministério da Saúde, 2003.

LOPES, Fernanda. Por que trabalhar com o quesito cor? 2007. Disponível em: <www.usp.br/ nepaids/quesito-cor.pdf $>$. Acesso em: jun. 2007.

PEREIRA, Isabel Brasil; LIMA, Júlio César França. Educação profissional em saúde. In: Escola Politécnica de Saúde Joaquim Venâncio/Observatório dos Técnicos em Saúde/ Fiocruz (Orgs.). Dicionário da educação profissional em saúde. Rio de Janeiro: EPSJV, 2006.

PEREIRA, Isabel Brasil; RAMOS, Marise Nogueira. Educação profissional em saúde. Rio de Janeiro: Editora Fiocruz, 2006.

RAMOS, Marise Nogueira. Indicações teórico-metodológicas para a elaboração de currículos na educação profissional de nível técnico em saúde. In: BRASIL. Ministério da Saúde. Profae: educação profissional em saúde e cidadania. Janete Lima de Castro (Org.). Brasília: Ministério da Saúde, 2002.

SAKAI, Márcia H.; CORDONI JR., Luiz. Os egressos da medicina da Universidade Estadual de Londrina: sua formação e prática médica. Espaço para Saúde, v. 6, p. 34-47, dez. 2004. Disponível em <www.ccs.uel.br/ espacoparasaude>. Acesso em: dez. 2005.
SANTOMÉ, Jurjo Torres. A educação em tempos de neoliberalismo. Porto Alegre: Artmed, 2003.

SANTOS, José Vicente Tavares dos. A construção da viagem inversa. Ensaios sobre a investigação nas ciências sociais. Caderno de Sociologia, v. 3, n. 3, p. 55-88, jan.-jul. 1991.

SANTOS, João B. F. dos; UCHOA, José de F.; MENELEU NETO, José. Precarização do trabalho de nível técnico em saúde no Nordeste: um enfoque nos auxiliares e nos técnicos de enfermagem. In: BRASIL. Ministério da Saúde. Organização Pan-Americana da Saúde. Observatório de recursos humanos em saúde no Brasil: estudos e análises. v. 2. Brasília: Ministério da Saúde, 2004.

SAVIANI, Dermeval. Trabalho e educação: fundamentos ontológicos e históricos. Revista Brasileira de Educação, v. 12, n. 34, p. 152-165, jan./abr. 2007.

SEN, Amartya. Desenvolvimento como liberdade. São Paulo: Companhia das Letras, 2000 .

STEVENSON, Willian J. Estatística aplicada à administração. São Paulo: Harbra, 1981.

UNIVERSIDADE ESTADUAL DE MONTES CLAROS (UNIMONTES). Faculdade de Medicina. Escola Técnica de Saúde de Montes Claros: estudo para implantação. Montes Claros: Unimontes, 1991.
Recebido em 03/11/2008

Aprovado em 08/05/2009 